\title{
Ignacio Manuel Altamirano y Vicente Riva Palacio: una amistad con fondo de parentesco tixtleco
}

Nicole Giron

INSTITUTO MORA

\begin{abstract}
La amistad de dos hombres célebres sirve para analizar las conexiones de las familias Riva Palacio y Guerrero con el Sur, que aún en nuestros días salen a flor en asuntos como el de los huesos de Cuauhtémoc.
\end{abstract}

L a amistad entre Vicente Riva Palacio e Ignacio Manuel Altamirauno de los rela pastón mas fan tásticos del escritor guerrerense: la Historia de los diamantes del Sur, inserta a manera de cuento interpolado en las "Revistas de la semana" publicadas los domingos 5 y 12 de junio de 1870 en el periódico El siglo XIX. ${ }^{1}$

El asunto, dotado de visos fabulosos, se encuentra estrechamente relacionado con las peripecias de la vida p. 272 .

${ }^{1}$ Altamirano, Crónicas, 1987, vol. vill, t. 2, del general Vicente Guerrero, hombre de extracción modesta, cuya fulgurante carrera política se debió solamente al valor y la inteligencia, haciendo de él un ejemplo de la revolución social que acompañó la extinción del dominio español sobre Nueva España. Compañero de armas de Morelos en todos los combates del Sur, irreductible guerrillero insurgente, Guerrero supo negociar con Iturbide para lograr la consumación de la independencia y alcanzó a ser máximo dignatario de la masonería yorkina al ocupar la presidencia de la república en 1829 . Su ejecución, en 1831, después de un jui- 
cio militarsumario logrado a consecuencia de su captura con una traición en el barco del marinero genovés Picaluga, fue el fruto de las intrigas del gobierno conservador de Anastasio Bustamante, y cimbró la vida política del país dejando un irredimible saldo de desconfianza en las filas liberales.

Vicente Guerrero era oriundo de Tixtla (hoy situado en el estado de su nombre), también pueblo natal de Ignacio Manuel Altamirano, y era el abuelo materno de Vicente Riva Palacio a quien nunca llegó a conocer puesto que falleció un año antes del nacimiento del niño. Aquellos tres personajes se encuentran por lo tanto unidos por un lazo de parentesco directo, consanguíneo aunque jamás disfrutado, o sólo ligado al paisanaje, que justifica la construcción de un parentesco ideológico, republicano e idealizado.

En la Historia de los diamantes del Sur, Altamirano, quien ofrece su relato a los lectores como un antídoto contra el tedio y los inconvenientes de la temporada de aguas, declara haberse visto obligado a revelar secretos hasta entonces conservados en silencio, porque el periódico conservador $\mathrm{La} \mathrm{Re}$ vista Universal había publicado sobre este tema pocos días antes ${ }^{2}$ un artículo dado a luz originalmente en febrero de 1833 por el "acreditado naturalista" Pablo de la Llave. En aquel texto, el científico mexicano refería su conversación con Vicente Guerrero, quien le había narrado en persona las circunstancias de su hallazgo; ade-

2 Ibid., p. 277 . Altamirano contestaba a un artículo publicado en La Revista Universal el 1 de junio de 1870 . más reputaba por certera la identificación, de las piedras (halladas en las bolas o "cocos" minerales referidos), como diamantes, con base en el peritaje de un conocido joyero capitalino, confirmado porel sabio don Andrés del Río y otros profesores del Colegio de Minería.

A pesar del enigma geológico que significaba la insólita procedencia de estas gemas, el hombre de ciencia no daba por imposible el fenómeno y mostraba curiosidad por reunir mayores informes sobre la localización de este "placer" y su entorno mineral.

Es indudable que con tales ingredientes cualquier mediano literato podía aderezar un cuento capaz de entretener al más exigente lector de crónicas dominicales, deslumbrándolo con el sueño de los incalculables tesoros que parecían estar al alcance de su mano.

Sin embargo el verdadero interés de la crónica de Altamirano no radica en la reutilización de la historia, ya conocida, de los diamantes del general Guerrero, misma que había sido recibida con cierto escepticismo en la capital, sino en el papel relevante de Vicente Riva Palacio e Ignacio Manuel Altamirano en la revitalización de este mito, conforme en todo punto a esa visión idealizada de México como una cornucopia desbordante de bienes y riquezas.

Sólo que en su versión actualizada el mito servía como testimonio de que los favores de la fortuna eran retribución a heroicos servicios prestados por un esforzado patriota, actor destacado en las recientes luchas contra los invasores de la patria: el general Vicente Riva Palacio. De paso, permitía 


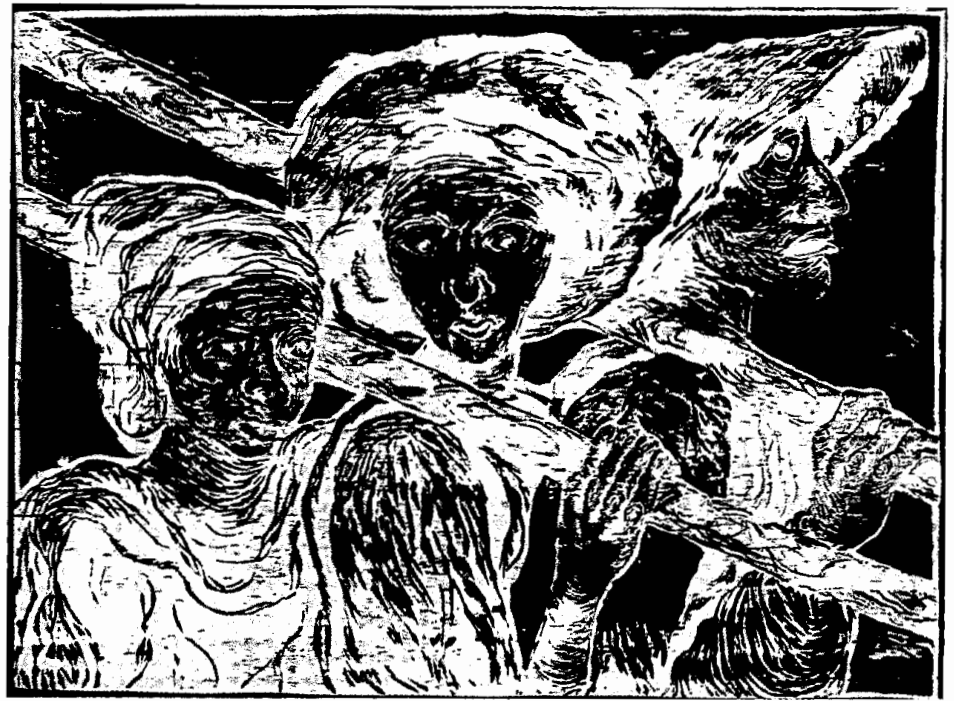

subrayar el linaje del joven general republicano y exaltar el prestigio de su persona.

En efecto, Vicente Riva Palacio aparece en este relato como una réplica del famoso insurgente, como el legítimo heredero no sólo de las riquezas de su abuelo, sino del afecto de los surianos, que ven resucitados en él la valentía y templanza de su antepasado, atributos compartidos democráticamente con un simple hijo del pueblo, Altamirano, igualmente bravo, quien conduce el peregrinar patriótico de su amigo por los caminos del Sur.

En el cuento, al guiar los pasos de Vicente Riva Palacio por la tierra de sus ancestros, Altamirano funge como un asesor del destino, como un mensajero protector que logra restablecer el contacto perdido entre el héroe y su gloriosa estirpe, facilitando su encuentro con los leales guardianes de aquella herencia fabulosa. De manera que el Sur recupera la continuidad de una tradición heroica y gloriosa que una fatalidad hostil -entiéndase reaccionaria- había querido arrebatarle. Al mismo tiempo halla en la persona de los providenciales montañeses, custodios del criadero de diamantes, la expresión de una poderosa identidad colectiva que simboliza la lealtad de un pueblo a sus ideales de libertad y su capacidad de unión en torno a la figura de un líder absoluto.

De tal suerte que este episodio de la vida real, similar en todo punto a un capítulo de novela de aventuras, constituye un cuento edificante, una divisa 
emblemática que presenta la imagen idealizada de sus protagonistas, capaz de legitimar -si fuese necesario-sus más exaltadas ambiciones. Vicente Riva Palacio, obviamente, y en menor grado Ignacio Manuel Altamirano, resultan ser los perpetuadores de Vicente Guerrero, el mártir republicano y liberal del Sur.

Paralelamente la Historia de los diamantes del Sur sirve para contrarrestar la percepción negativa de una región bronca, de recia tradición combativa, considerada en 1870 como un avispero político. De modo que Vicente Riva Palacio, heredero político al mismo tiempo que genético de Vicente Guerrero, y Altamirano - colocado en el papel de fiel escudero-, se transforman en paladines de la causa del Sur, precisamente en el momento en que el gobernador del estado de Guerrero, el general Francisco O. Arce, designado por Benito Juárez para restablecer el orden en aquella explosiva entidad, enfrentaba un fuerte conflicto con los habitantes de Tixtla, todavía entonces capital del Estado, y veía nuevamente puesto en entredicho el éxito de su política de pacificación.

En aquellos días parecía que nadie buscaba un nuevo gobernador para la entidad, y el gobierno juarista no mostraba intenciones de modificar su línea de conducta respecto a este espinoso caso, ligado al equilibrio de las fuerzas políticas en la lucha desatada por el control del gobierno federal desde la convocatoria de 1867 . Pero precisamente ahí radicaba el interés de la crónica, aparentemente anecdótica, de Altamirano: introducir en un juego político que parecía cerrado el fermento de nuevas propuestas. Y no cualquier propuesta; nada menos que la del nieto de Vicente Guerrero, un republicano intachable con probada capacidad militar que había demostrado sus dotes de administrador en las penurias de la guerra, un candidato de primera magnitud cuyos méritos alcanzaban e incluso rebasaban, los del general Arce. Además, su reciente renuncia al cargo de magistrado a la Suprema Corte lo dejaba "libre" para mayores eventualidades, y su vieja amistad con el general Vicente Jiménez le daba excelentes armas para negociar, $\sin$ herir susceptibilidades, el regreso del rebelde a la legalidad. Un "articulito" como el presente venía pues muy a propósito para recordar, tanto en el Sur como a nivel nacional, las capacidades, los antecedentes, el prestigio y la lealtad republicana del general Vicente Riva Palacio.

De modo que podemos distinguir fácilmente, bajo el ropaje de una amena lectura de entretenimiento, la intención política del relato, incluido con sospechosa inocencia narrativa en una publicación de crónicas dominicales.

Por medio de aquella producción periodística, en un género literario menor e inocuo, el fiscal de la Suprema Corte de Justicia -Ignacio Manuel Altamirano-quien en 1868 había anunciado con platillos y bombos su firme propósito de alejarse de la política y su decisión de consagrarse tan sólo al cultivo de la bella literatura, regresaba a las andadas. Se inmiscuía otra vez en el juego de la política nacional aunque de una manera sutil, insinuante, como convenía a un alto funcionario de la 
Federación que no debía intervenir directamente en el manejo de la opinión pública.

Es pertinente destacar la ambigüedad de esta actitud periodística porque está en el meollo de la amistad que por tantos años unió a Ignacio Manuel Altamirano y a Vicente Riva Palacio. Ambos usaron su pluma para ponerla al servicio de la política, quizá más que al servicio de la literatura. O mejor dicho, ambos nunca concibieron su quehacer literario como ajeno a la coyuntura política que atravesaban. La expresión literaria era parte de su combate para influir sobre el criterio de los lectores, difundiendo directa e indirectamente valores, opiniones y juicios. Por ello ambos cultivaron el periodismo y usaron las revistas o los diarios 3 como órganos de un apostolado social que integraba la literatura en todas sus formas: poesía, novela, drama, historia, crítica literaria, periodismo político, etc., como instrumento privilegiado -principal o secundario según los momentos- de su participación en la vida política y social del país.

Podríamos decir que ambos fueron políticos antes que hombres de letras, y hasta cierto punto hombres políticos frustrados, que no vieron plenamente colmadas sus aspiraciones, por cierto bien elevadas. Sin embargo fue por la vía de las letras-que ambos consideraron una actividad accesoria para

\footnotetext{
3 'Tanto Vicente Riva Palacio como Altamirano colaboraron en un gran número de periódicos, pero no pueden separarse sus nombres, por lo menos de dos publicaciones famosas: $L a$ Orquesta para Riva Palacio, El Renacimiento para Altamirano.
}

el logro de los propósitos políticos o un consuelo después de los fracasoscomo la historia les concedió la grandeza que hoy se les reconoce en el panorama de las glorias nacionales. De ahí que el estudio de estas personalidades obligue a una navegación incesante entre los parajes de la literatura y los de la política, en una modalidad anfibia de la historiografia que debe tomar prestadas sus armas tanto a la crítica literaria como a la historiográfica.

Las "revistas" que nos interesan constituyen la evocación más explícita del entrañable compañerismo entre Vicente Riva Palacio e Ignacio Manuel Altamirano, en 1866. Compañerismo destinado a crecer y a fincar una amistad, como lo comprueban las numerosas menciones que de ella encontramos en los escritos periodísticos de Altamirano ${ }^{4}$ y que nos ayudan a descu-

${ }^{4}$ Citemos, entre otros, la despedida que formula en su "Revista de la Semana" del 10 de julio de 1870: "Mi amigo el general Riva Palacio ha partido antier para Europa. Su partida me ha causado tristeza. Somos amigos desde la juventud, hemos sido compañeros en los días de prueba. ¡Qué tenga un feliz viaje! ¡que pronto regrese! Altamirano, Crónicas, 1987, vol. vIII, t. 2 , p. 338. O bien este recuerdo elogioso y lleno de afecto, mencionado en la evocación del estudio de Alfredo Bablot que ocupa parte de la "Revista de la semana" correspondiente al 25 de septiembre de 1870: "Alguna vez Riva Palacio, en esos alegres ratos que se pasan inter pocula, ha imitado con mucha gracia semejante estilo (el de mezclar una cita histórica, un verso antiguo o un dicho célebre a la conversación parodiando su sentido serio) y era de oírse, cómo él y Alfredo Bablot entablaban un diálogo delicioso en lenguaje erudito y erizado de citas, rivalizando ambos en la prontitud y brevedad de las respuestas y del ataque, no menos que en la sutil delicadeza y en la urbanidad (celeritasque et brevitas et respondandi et accesendi subtili 
brir los hilos paralelos de dos destinos hermanados sólo por la intensidad de convicciones ideológicas profundamente afines.

Según lo aclara Altamirano, Vicente Riva Palacio hizo un viaje al Sur en marzo y abril de 1866 con el fin de incorporarse a las filas surianas 5 o por 10 menos de obtener de Juan Álvarez y de su hijo Don Diego, a la sazón y respectivamente comandante militar y gobernador del estado de Guerrero, los apoyos necesarios para armar a un grupo de soldados auxiliares en alguna parte del Estado de México. De hecho, por aquellas fechas Vicente Riva Palacio acababa de ser separado del mando de las tropas republicanas de Michoacán a raíz de una discutible decisión del general Régules, militar experimentado, de origen español, a quien el presidente Juárez prefirió entregar la responsabilidad de esas fuerzas.

En realidad la elección de Juárez se debía en parte al delicado asunto de la prolongación de su periodo presidencial en noviembre de 1865. Como es sabido, el general Jesús González Ortega, quien había sido electo presidente de la Suprema Corte de Justicia en 1862 y por tanto se encontraba constitucionalmente en posición de sustituir al primer mandatario de la nación en caso de necesidad, se creyó con derecho a reemplazar a Juárez al término de su mandato. Cuando éste anunció la decisión de prolongar la dura-

venustate atque urbanitate conjunta), como lo exigía el príncipe de la elocuencia romana en el libro primero de su Orador". Ibid., p. 459.

5 Ibid., p. 283. ción de su periodo gubernamental, ya que era imposible efectuar elecciones en un país invadido por fuerzas ex. tranjeras, González Ortega manifestó públicamente, desde Estados Unidos, en donde se hallaba de viaje, su inconformidad con esta resolución y externó su pretensión presidencial. Si bien es cierto que su posición encontró algunas simpatías, la mayoría de los mexicanos republicanos optaron por sostener a Juárez y avalar su permanencia en la primera magistratura de la nación. 6

En este contexto es donde hay que situar la decisión de Juárez de atribuir al general Nicolás de Régules y no a Vicente Riva Palacio el mando militar en Michoacán después de la trágica desaparición del general Arteaga. Tal resolución estaba encaminada a impedir que un jefe joven, impulsivo, prestigioso, lleno de iniciativa y susceptible de simpatías orteguistas, pudiese ocupar un puesto elevado en el mando militar y secundar en cualquier momento las intenciones posiblemente levantiscas de aquél.

Riva Palacio, que había militado desde la primera hora y con toda generosidad en las filas republicanas, que había reorganizado al ejército del Centro ${ }^{7}$

\footnotetext{
${ }^{6}$ Altamirano apoyó sin reticencias a Juárez en esta circunstancia: "Ha hecho usted bien, muy bien, a nuestro juicio, en haber decretado su permanencia en el alto puesto en que ha sabido defender los derechos de la patria. Éste era el deseo del gran partido republicano. Aquí con ese respeto la opinión es uniforme, sin una sola excepción". Carta de Altamirano a B. Juárez, 12 de marzo de 1866, Epistolario, 1992, vol. XXI, t. 1, p. 151.

${ }^{7}$ Ibid.
} 
después de la derrota republicana de Tacámbaro y la ejecución del general Arteaga por el sanguinario jefe imperialista Méndez, ${ }^{8}$ que había ganado a pulso la estimación de sus hombres cuyos oficiales lo habían designado por votación unánime para ocupar el mando superior, ${ }^{9}$ vio menospreciadas sus fundadas aspiraciones a un alto puesto a la cabeza del ejército del Centro. Sin embargo supo encarar dignamente esta marginación, y acató las órdenes superiores sin pestañear, ${ }^{10}$ aun cuando el resabio amargo nacido de aquella coyuntura marcara para siempre su sensibilidad e intervino seguramente como un elemento no despreciable en su posterior inclinación al porfirismo.

La visita de Vicente Riva Palacio al Sur, además de alejarlo de un posible conflicto de autoridad en los antiguos

8 Véase acerca de este episodio el discurso pronunciado por Altamirano en el panteón de San Fernando el 17 de julio de 1869 en el acto de depositarse alli las cenizas de los beneméritos generales José María Arteaga y Carlos Salazar, publicado en El Siglo XIX del 21 de julio de 1869. Discursos, 1986, vol. I, p. 162.

9 Ibid., p. 156. En esta carta a Juárez, Altamirano desarrolla un largo alegato en favor de Riva Palacio destacando sus méritos, supone que la información de Júarez acerca de la situación en Michoacán es incompleta, y externa con viveza su personal decepción ante la marginación de Riva Palacio. Menciona que éste se siente "mortificado" y desairado por Juárez al no haber sido notificado directamente de la obligación de entregar el mando de sus tropas. En esta cartí como en otras escritas a Juárez, se percibe claramente la preocupación de Altamirano por informar al presidente refugiado en Paso del Norte del curso de los acontecimientos en el Sur, Michoacán y Oaxaca.

${ }^{10}$ Ibid., p. 155. territorios de su mando, tenía probablemente, en el ánimo del joven general, visos de regreso a sus orígenes, de peregrinación sagrada hacia la tierra de sus ancestros. En la adversidad política, êl buscaba el apoyo de los Álvarez, de don Juan sobre todo, quien había ofrecido siempre a su familia, desde las montañas del Sur, el refugio de su protección ${ }^{11}$ y había sido constante compañero de armas y amigo entrañable de su abuelo.

Para los Álvarez la visita de Vicente Riva Palacio como la de Porfirio Díaz en octubre de $1865^{12}$ planteó un problema delicado. Encargados por Juárez de defender la causa republicana en el Sur, los Álvarez, cuyo territorio permaneció en gran medida libre del control enemigo, debían apoyar a todos los partidarios del gobierno de Juárez dispuestos a luchar contra la intervención francesa y el imperio. Sin embargo, a la hora de actuar se mostraron sumamente cuidadosos de no favorecer con la entrega directa de armas o municiones la formación de grupos armados cuya lealtad al gobierno constitucional pudiera volverse problemá-

11 Juan Álvarez cuidó de los intereses de la viuda de Vicente Guerrero; en particular se ocu. pó en varias ocasiones de la crianza y venta de los ganados de los ranchos de Xaltianguis, Tierra Colorada y Amatlán, arrendados por Vicente Guerrero -y posteriormente por su viuda Guadalupe Hernández-a la Junta de hermanos de la Cofradía del Santisimo de la parroquia de Tixtla. Archivo de Mariano Riva Palacio, Austin, University of Texas Library, doc. 859,963 y 215 , 216 (microfilms en el Instituto Mora).

12 Altamirano informó acerca de la presencia de Porfirio Díaz en La Providencia en su carta a Juárez del 30 de octubre de 1865 . Altamirano, Epistolario, 1992, vol. XXI, t. 1, p. 143. 
tica algún día, o cuya combatividad pudiese opacar sus propios esfuerzos. De tal suerte que habian optado por una política de promesas verbales, generosas pero poco efectivas. ${ }^{13}$

Por entonces Ignacio Manuel Altamirano, investido de una gran autoridad moral en su calidad de diputado constitucional por Guerrero, gozaba de la amistad de los Álvarez y vivía en su hacienda de la Providencia, ${ }^{14}$ centro político del estado, situada en las estribaciones de la Sierra Madre, que dominan el litoral de Acapulco. Ejercía cerca de aquellos personajes un papel de consejero político y de vocero republicano: pronunciaba discursos patrióticos, ${ }^{15}$ se carteaba con Juárez a quien mantenía informado de los principales acontecimientos militares y escribía algunos artículos destinados a los diarios de Tixtla, la capital del estado, donde había una imprenta, oa algunos de los periódicos en idioma español de San Francisco. ${ }^{16}$ En ellos

13 Véase la carta de Altamirano a Juárez con fecha 27 de octubre de 1866. Ibid., p. 166. Acerca de la actitud de los Álvarez con Porfirio Díaz y Vicente Riva Palacio véanse también los artículos publicados por Altamirano acerca del enfrentamiento entre Diego Álvarez y el general Vicente Jiménez en El Correo de México, durante los meses de noviembre y diciembre de 1867 , asi como el combate verbal que sostuvo con Diego Álvarez en 1868 mediante remitidos en El Siglo XIX. Altamirano, Periodismo político, 1989, vol. XVII, t. 1, pp. 118, 119-120-121 y 163 .

14 Ibid., vol. XxI, p. 170; Periodismo Politi. co, 1989 , t. 1 , p. 162 .

15 Tres de estos discursos el 5 de mayo de 1865,16 de septiembre del mismo año y 16 de septiembre de 1866, en Altamirano, Discursos, 1986, vol. I, pp. 111-150.

16 Véase la carta de Altamirano al general Vicente Jiménez del 1 de noviembre de 1866 , defendía las principales tesis del gobierno republicano, a saber: la iniquidad de la invasión extranjera perpetrada contra México cuyo legítimo gobierno era perseguido en su propio territorio por soldados extranjeros y la ilegitimidad de los gobiernos procedentes de ella, haciendo patente con su actividad periodística la existencia, en la república invadida, de una "opinión pública" favorable al gobierno de Juárez, incesantemente desacreditado por la propaganda francesa e imperial.

Sin lugar a dudas resultó ser, en el entorno de Juan y Diego Álvarez, la persona más idónea para acompañar al joven general despechado cuyo sostén político podía representar un delicado problema para los señores Álvarez. Altamirano era nativo de Tixtla y conocía perfectamente los caminos de la entidad que había recorrido frecuentemente en los años recientes, desde su pueblo natal a La Providencia y Acapulco o de allí a Iguala y México. Era abogado de formación, como Riva Palacio, y cultivaba las bellas letras como él. Eran casi de la misma edad, pues Vicente era mayor dos años, y ambos habían ocupado un escaño en el segundo Congreso Constitucional de la nación en 1861 y 1862, en donde habían dado sus primeros pasos en la vida parlamentaria y habían figurado en las filas oposicionistas, llevados de la misma admiración por el general Jesús González Ortega, el vencedor de

Eptstolario, 1992, vol. XIX, t. 1, p. 171; así como un brindis pronunciado por Altamirano en Acapulco en julio de 1865 y publicado en $E l$ Nuevo Mundo de San Francisco, California. Pertodismo Político, 1989, p. 61. 
Miramón en Calpulalpan. Sus rúbricas aparecieron en la famosa petición de los 51, mediante la cual un grupo de diputados - "actuando como personas particulares" - había solicitado al presidente Juárez que renunciara al cargo para el cual acababa de ser electo constitucionalmente, considerándole "inepto" para ejercerlo. En su momento la iniciativa había suscitado un gran escándalo, pronto ahogado por la reacción de otros 52 diputados quienes refrendaban su adhesión al presidente en una carta donde le solicitaban permaneciera en el poder. Después de este episodio en el que culminó la ingenuidad -o la mala fe-de una oposición dispersa y de todos modos inoperante para implantar en México un parlamentarismo exótico, ambos habían regresado a posiciones más cuerdas pero sin abandonar el vigor de sus críticas a un gobierno que les parecía demasiado contemporizador. Empero ambos habían cerrado filas en torno al equipo gobernante luego de la amenaza de intervención extranjera y con encendido patriotismo habian acudido a las armas. ${ }^{17}$

${ }_{17} \mathrm{El}$ periódico Le Trait d'Union anunciaba el 17 de abril de 1862 que Vicente Riva Palacio había recibido autorización para organizar una guerrilla destinada a luchar contra las tropas de intervención en el distrito de Chalco y contaba para ello con la cooperación de los hacendados de la región. El mismo número saludaba la primera entrega de La Chinaca, un periódico "pequeño, escrito única y exclusivamente para el pueblo, y atacando a los franceses". Por otra parte, evocando el año de 1862 , Altamirano escribía: "El ministro Doblado nos envió a nosotros su comisión para arreglar el contingente del estado [de Guerrero] que debía venir al Ejército de Oriente. Esto fue en 1862. El ministro nos dio
Riva Palacio se alistó para participar en la defensa de Puebla en 1863, ocupando altas responsabilidades en el estado mayor del general González Ortega ${ }^{18}$ a quien Juárez había encarga. do el mando de aquella plaza, llave del acceso al altiplano y al control de la capital del país.

En cuanto a Altamirano, quien había emprendido la ruta hacia el Sur para formar allá un batallón de fuerzas auxiliares, sólo su reelección como diputado por Guerrero al tercer Congreso Constitucional le impidió realizar sus propósitos bélicos, conduciéndolo a reunirse en San Luis Potosí con el núcleo duro del republicanismo.

Más tarde Riva Palacio, nombrado gobernador y comandante general del 1er. distrito del Estado de México, se había dirigido a Michoacán donde estableció su cuartel general en las montañas de Zitácuaro, ${ }^{19}$ redactando en plena guerra periódicos como El Monarca y El Pito Real para fustigar a los traidores y a la administración imperial al tiempo que exaltaba la resistencia republicana. Después de organizar de la nada un cuerpo auxiliar del

para don Diego Álvarez 30000 pesos en órdenes sobre el Manzanillo." Ibid., p. 113.

${ }^{18}$ Altamirano, refiriéndose a esta época, escribió en una carta a Juárez el 12 de marzo de 1866: "Yo era ya coronel de la Guardia Nacional, nombramiento que me dio este gobierno [del Estado de Guerrero] cuando el sitio de Puebla, al que yo iba a encerrarme con Pinzón; pero llegué tarde, después de la toma de San Javier y me quedê en el Congreso." Epistolario, 1992, vol. XXI, p. 153.

19 Para esta etapa de la vida de Vicente Riva Palacio, véase el testimonio de Eduardo Ruiz, Historia de la guerra de Intervención en Michoacán, 1973, pp. 72-76. 


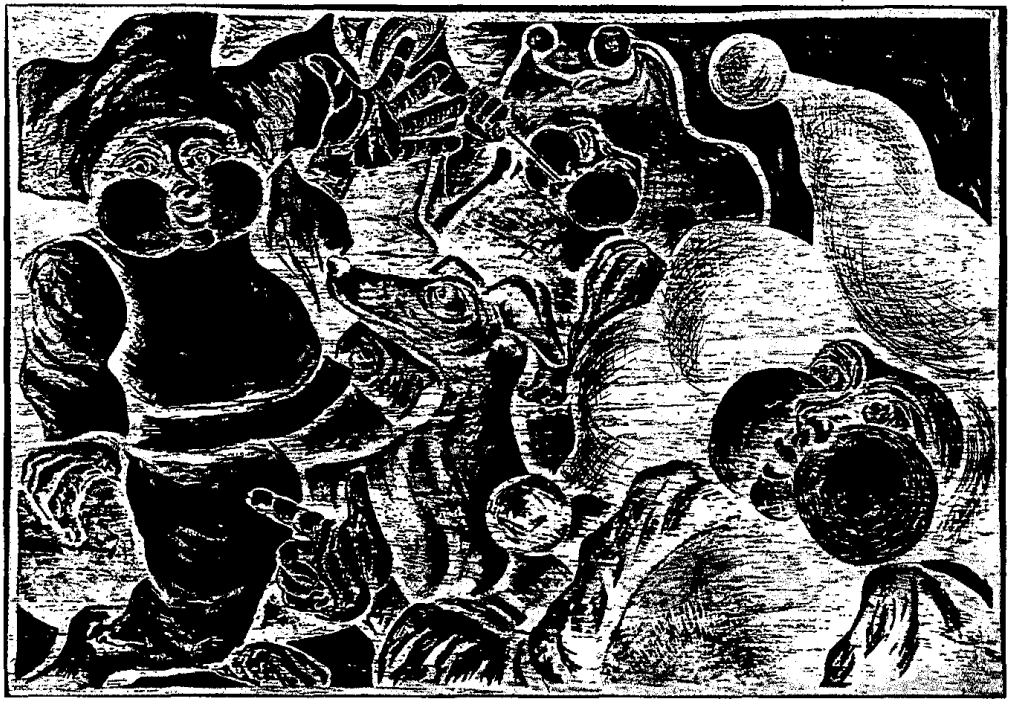

ejército republicano del Centro, duramente golpeado por la traición de algunos de sus jefes adheridos al imperio de Maximiliano, Riva Palacio logró restablecer la disciplina y la combatividad en aquellas huestes desalentadas por las derrotas así como por la aprehensión y el fusilamiento de su máximo jefe, el general Arteaga. Mientras tanto Altamirano ocuparía en el Sur, cerca de los Álvarez, el papel que hemos evocado.

La reunión de Vicente Riva Palacio e Ignacio Manuel Altamirano durante la primavera de 1866, después de un prolongado intercambio de correspondencia que mantenía viva la comunicación -y la inteligencia- republicana frente a un enemigo poderoso, tuvo un aspecto providencial. Después de tantas experiencias definitorias en trayectorias paralelas, ambos estaban listos para transformar un encuentro casual en elección deliberada. Sus ideales liberales y sus convicciones patrióticas los hermanaban a pesar del abismo social que hubiera podido distanciar al hijo de un relevante hombre político mexicano, varias veces ministro y gobernador, con el de un humilde artesano pueblerino.

Este compañerismo se percibe claramente en la Historia de los diamantes del Sur, y se despliega como un preludio a la convergencia de destinos que iba a acercarlos más todavía en la experiencia definitiva del sitio de Querétaro, durante la primavera de 1867 , y los conduciría por el camino de la fraternidad de las armas y de la mi- 
litancia política a distanciarse sin remedio del grupo juarista.

De la misma manera que Altamirano fue el conducto por el cual una "señora de la costa" se acercó a Vicente Riva Palacio para propiciar el "contacto" de éste con los montañeses, fieles cuidadores del criadero de diamantes, vía posible de un fabuloso enriquecimiento, también fue el introductor de Vicente Riva Palacio al mundo de Tixtla, la patria de sus antepasados maternos.

Alli permanecieron 15 días con el general Vicente Jiménez, la figura militar y política más relevante del lugar; "pariente de él y mío", escribirá Altamirano en una de sus cartas a Juárez, ${ }^{20}$ explicando: "pues yo soy también tixtleco y pertenezco como Riva Palacio y como Jiménez, a la familia del general Guerrero".

En una pequeña ciudad como Tixtla, más bien un pueblo grande, las relaciones de parentesco son intrincadas y casi todas las familias están emparentadas por vía consanguínea o política. Tal era el caso de Vicente Riva Palacio, de Vicente Jiménez y de Ignacio Manuel Altamirano.

Vicente Riva Palacio era tixtleco de doble cepa, nieto de Vicente Guerrero y de María Guadalupe Hernández, "La Generala", hijo mayor de la única descendiente de ambos: María Dolores Guerrero Hernández, por lo cual se encontraba relacionado con $\mathrm{mu}$ chas familias del lugar. Como el niño Vicente había nacido en la ciudad de México, poco después del fusilamien-

${ }^{20}$ Altamirano, Epistolario, 1992, vol. XXI, t. 1, p. 157. to de su abuelo, nunca había vivido en la tierra de sus abuelos ni la había visitado, de suerte que todos los que se consideraban emparentados con su familia quisieron festejar el retorno al pueblo del vástago mayor de su máximo héroe:

La plaza de Tixtla como la de Chilpancingo no ha sido profanada jamás por la huella de reaccionarios, traidores $\mathrm{o} \mathrm{im}$ perialistas. Así es que en aquel recinto sagrado donde ha flameado invicto el estandarte de la república, todo conservaba un aspecto alegre y tranquilo. Los habitantes se entregaban a los placeres de sus fiestas como siempre y el estar cerca el enemigo no era causa bastante para turbar su regocijo.

Así, pues, la fiesta del 5 de abril (cumpleaños de Riva Palacio) fue solemnizada con gran pompa y en festines y entusiasmo se pasaron los pocos días que permanecimos allí. ${ }^{21}$

De hecho todavía vivían en Tixtla diversos sobrinos o sobrinos nietos de Vicente Guerrero, quienes acogieron a su primo con regocijo, entre ellos el presbítero Prudencio Catalán, hijo de María Dolores Guerrero Saldaña, una de las hermanas del prócer de la independencia, quien se había seguido carteando afectuosamente con "La Generala" y su hija, mucho tiempo después de la muerte de Vicente Guerrero. ${ }^{22}$ Él

21 Altamirano, Crónicas, vol. viII, t. 2, p. 289.

22 Citemos entre otras cartas la que Prudencio Catalán mandó a su tía Guadalupe Hernández y a su sobrina Dolores Guerrero el 21 de septiembre de 1842 anunciándoles el próximo enlace matrimonial de su sobrina Doloritas (Guillén Velis) con el juez de Letras Agustín Pérez Gavilán, mismo al que asistieron los padres de Mar. 
había recogido en su casa a su hermana Feliciana cuando enviudó y a una sobrina de ésta, Dolores Guillén.Velis, misma que se había convertido en suegra de Ignacio Manuel Altamirano cuando éste casó con Margarita Pérez Gavilán en 1859. Otro sobrino del héroe independiente, Pedro González, se había casado con María Gertrudis Bello, una tía de la madre de Altamirano, a su vez prima hermana de la suegra del general Vicente Jiménez. ${ }^{23}$ En una palabra, la extensa red tixtleca de parentesco y de alianzas había movilizado todas sus ramificaciones para desplegar su tradicional hospitalidad:

Le hicieron grandes honores, no sólo en memoria y honor de su ilustre ascendiente, sino a causa de sus altos hechos y sobre todo de su reciente victoria de Uruapan, porque fue él y no el señor Régules quien mandó en jefe en esta batalla y quien concibió el pensamiento de ir a darla. ${ }^{24}$

Sin embargo, según refiere Altamirano, la identificación colectiva con el retoño del heroico Guerrero no estu-

garita Pérez Gavilán, la futura esposa de Altamirano. Archivo de Mariano Riva Palacio, Austin University of Texas Library, doc. 1341 (microfilms en el Instituto Mora).

${ }^{23}$ El señor Melchor García Reynoso, nativo de Tixtla, ha realizado acuciosas investigaciones en los registros parroquiales de esta ciudad, esenciales para desentrañar algunas relaciones de parentesco en Tixtla. Transcribió una parte de sus indagaciones relativas a Altamirano publicadas en Genealogía, 1991. Son sus indicaciones las que sustentan las afirmaciones aquí vertidas.

${ }_{24}^{4}$ Carta de Altamirano a $\mathrm{B}$. Juárez del 4 de agosto de 1866, Epistolario, 1992, vol. XXI, p. 157. vo exenta de tristeza, pues a pesar de su estoico patriotismo todos notaban que Vicente estaba "apesumbrado" cuando respondía a cuantos lo interrogaban acerca de su situación:

El gobierno sabe lo que hace y si el presidente me hace descender a capitán de una compañía o a soldado raso, me resignaré sin observación porque me toca obedecer y en estos momentos, el que no tiene abnegación y obediencia es un traidor. ${ }^{25}$

Al transcribir estas palabras en una carta dirigida a Benito Juárez desde La Providencia en agosto de 1866, Altamirano se empeñaba, como lo había hecho en el mes de marzo anterior, en defender a su amigo. Fingía achacar al general Régules toda la responsabilidad de la "injusta destitución" de Riva Palacio, aun cuando era obvio que la decisión de separar a éste del "gobierno de Michoacán y aun del de México" 26 no había podido aplicarse a espaldas del presidente, y afirmaba rotundamente para eximir de toda sospecha al nieto de Guerrero: “...puede Ud. estar seguro de que es tan adicto al gobierno y a la persona de usted como el que más lo sea".

Esfuerzo generoso pero inútil, ya que Juárez conservaría sus prevenciones y acabaría uniendo a ambos literatos en un mismo trato de prudente suspicacia, reconociéndoles talento intelectual y capacidad de jurisconsultos pero sin concederles más honores que los estrictamente ganados en los campos de batalla o en las lides electorales.

${ }^{25}$ Ibid., p. 158.

${ }^{26}$ Ibid., p. 160. 
Quizá la ruptura que se haría manifiesta entre aquellos liberales después de la convocatoria de 1867 se inició cuando Altamirano y Riva Palacio, olvidando que eran letrados para volverse verdaderos hombres de armas, asumieron su autonomía de jefes guerrilleros y se unieron sin esperar permisos para acabar con los enemigos de la patria y del príncipe usurpador, restableciendo por la fuerza la legalidad republicana.

Así lo hizo Altamirano a finales de 1866 al lanzarse al asalto de las altas tierras del Distrito Federal después de una ruptura tormentosa con Diego Álvarez, todavía a cargo de la gubernatu. ra de Guerrero. Jefe militar improvisado, usó exitosamente, a la cabeza de un cuerpo de caballería de 400 hombres, el diploma de coronel que le había otorgado el presidente Juárez en octubre del año anterior, y después de ganar varios encuentros contra los imperialistas se unió con sus soldados a la brigada del general Vicente Jiménez, la cual se sumó, en Toluca, a las fuerzas de Vicente Riva Palacio.

De allí salieron todos en marzo de 1867 para participar en el sitio de Querétaro, donde las tropas al mando de Riva Palacio, y señaladamente la brigada sureña del general Vicente Jiménez, desarrollarian un papel relevante entre los miles de soldados republicanos congregados en este punto para abatir el imperio. ${ }^{27}$

27 Varios textos de Altamirano se refieren al sitio de Querétaro. En ellos menciona muy señaladamente su relación de subordinación con el general Vicente Riva Palacio, expone su participación en los combates, su pertenencia tempo. ral al secretariado del general Escobedo, coman-
Les tocó defender las posiciones de la línea sur del cerco contra las cuales se concentraron finalmente las más decididas ofensivas de los sitiados, de modo que la brigada de Vicente $\mathrm{J}$ ménez quedó diezmada después de combatir repetidas veces con denuedo y en ocasiones al arma blanca. En alguno de esos enfrentamientos el coronel Altamirano se comportó con tal arrojo que su nombre fue citado en la orden del día del ejército republicano. ${ }^{28}$

Durante el sitio, tanto Vicente Riva Palacio como Ignacio Altamirano y los demás jefes militares reunidos en los alrededores de la plaza tuvieron tiempo pará estrechar la sociabilidad tan peculiar de los oficiales de guerra, siempre en riesgo de perder la vida y siempre ansiosos de olvidar semejante evidencia. Según toda probabilidad, vivieron el momento aterrador de los combates sin dejar de ser letrados y poetas, confrontados en la intensidad emocional de una sensibilidad refinada, a las pulsiones más primitivas del

dante en jefe del ejército sitiador, su encuentro con el príncipe Maximiliano después de su prisión. Entre otras cosas, Altamirano señala que fue el general Vicente Riva Palacio quien escoltó a Maximiliano hasta su prisión después que éste entregara su espada en señal de rendición al general Mariano Escobedo. Alli Maximiliano "regaló a Riva Palacio el caballo que montaba y le suplicó que conservase a su lado a un asistente jovencito, vestido de azul, que parecía muy afligido con la desgracia de su señor". Altamirano, Crónicas, 1989, vol. viI, t. 2, pp. 256-263; Obras históricas, 1986, vol. II, pp. 259-281.

${ }^{28}$ Parte de operaciones rendido a la superioridad por el general Mariano Escobedo, Jefe del Ejército del Centro, con fecha 3 de mayo de 1867, citado por Vicente Fuentes Díaz, Ignacio, 1988 , p. 145. 
hombre: el miedo, la furia asesina, el horror ante la muerte y la destrucción.

Para ambos, aun cuando hubieran participado en las tareas más protegidas del estado mayor, Altamirano en el secretariado del general en jefe, y Riva Palacio en todas las reuniones de los altos oficiales de estado mayor, la experiencia de Querétaro fue determinante. Complementó sus vivencias de guerrilleros republicanos, entrenados a luchar con ingenio y arrojo en medio de las escaseces de la guerra, con la práctica de una vida militar organizada con mayores recursos y profesionalismo. Ni uno ni otro olvidarían las lecciones que les enseñó su participación en los ámbitos del alto poder militar, donde no se jugaba con el fuego de los debates parlamentarios sino con la vida y la muerte. Quizás en razón de esta ruda experiencia conservarian para el general Porfirio Díaz una admiración superior a la que pudo jamás merecerles la política del licenciado Benito Juárez.

Con aquella fraternidad de las armas compartidas en el fragor de los combates, entre nubes de pólvora y salpicaduras de sangre, se consolidó la amistad gestada entre las palmeras del Sury los festejos tixtlecos, creando entre Vicente Riva Palacio e Ignacio Altamirano una convergencia de impresiones y de apreciación que duraría hasta el triunfo del porfirismo en 1876.

Vencido el emperador en Querétaro, Vicente Riva Palacio y sus soldados se habían precipitado hacia la capital para reforzar el ejército de Oriente que, al mando de Porfirio Díaz, sitiaba la ciudad de México. Altamirano, enfermo de disentería, formaba parte de estas fuerzas pero tuvo que quedarse en Toluca para restablecer su salud. ${ }^{29}$ Sólo un motivo de esta gravedad lo mantuvo alejado de las últimas acciones militares republicanas, impidiendo su regreso al Sur con los restos de la brigada de Jiménez. Ésta fue la razón por la cual se mantuvo hasta cierto punto marginado del severo conflicto surgido entre los combatientes del sitio de Querétaro y Diego Álvarez, ansioso por atribuirse una gloria militar que no había cosechado en el sitio de Puebla.

Restablecido, Altamirano se reincorporó a la vida civil y se lanzó como Vicente Riva Palacio a la actividad periodistica. Ambos disintieron de la convocatoria lanzada por Juárez en agosto de 1867 y militaron -infructuosamente-a favor de la candidatura presidencial de Porfirio Díaz.

En ese mismo año ambos resultaron electos como magistrados de la Suprema Corte de Justicia de la nación $y$, en febrero del año siguiente, pasaron a formar parte de la máxima instancia del poder judicial. Fue entonces cuando aquellos soldados poetas olvidaron sus disposiciones marciales $y$ regresaron de consuno a la frecuentación de las Pandectas y al estudio del derecho constitucional, aunque sin renunciar ni uno ni otro a la práctica del periodismo político o cultural, según los casos.

Ambos propiciarían activamente el renacimiento de la vida literaria, iniciando uno y promoviendo el otro las

29 Véase carta de Ignacio M. Altamirano a Manuel Parra del 5 de julio de 1867, en Altamirano, Epistolario, 1992, vol. XXI, t. 1, p. 227. 
famosas Veladas Literarias, destinadas a reanimar la "república de las letras", dividida por creencias políticas antagónicas. Ejercieron en el combate de las ideas el mismo compañerismo que los había unido en los campos de batalla, secundándose el uno al otro en la creación de revistas literarias como $E l$ Renacimiento ${ }^{30}$ o de asociaciones culturales, científicas o cívicas. ${ }^{31}$ Desde los territorios de la novela, de la crónica, ${ }^{32}$ de la crítica literaria, de la poesía, ambos se esforzaron a lo largo de los años por revivir y hacer prosperar en México el cultivo de las bellas letras y del periodismo pues creían que en ello descansaba la posibilidad de di-

${ }^{30} \mathrm{El}$ nombre de Vicente Riva Palacio figura en la lista de colaboradores que encabeza los dos tomos de El Renacimiento pero ninguna obra de él vio la luz ahí, aunque cuanta obra suya se publicara durante el tiempo de vida de la revista fue reseñada en sus crónicas por Altamirano.

${ }^{31}$ En el libro colectivo Ensayos literarios de la Sociedad Netzahualcoyotl (Imp. de Ignacio Escalante, México, 1869), Altamirano publicó algunas de sus poesias junto con otros miembros de la Sociedad: Manuel Acuña, Agustín Cuenca, Antonio Salazar, Francisco Granados Maldonado y Martín Fernández de Jáuregui. Apareció allí su poema Al Atoyac con la dedicatoria "A mi querido amigo Vicente Riva Palacio".

32 Altamirano reseñó puntualmente los trabajos de Vicente Riva Palacio. Por ejemplo en su "Crónica de la semana" del 13 de noviembre de 1869 en El Renacimiento, anuncia la publicación de Los Dolores del Pueblo, una "prolonga. ción" de Los Piratas del Golfo, e informa de la colaboración de Riva Palacio con Manuel Payno para redactar El Libro Rojo. Igualmente en su "Revista de la Semana" del 29 de mayo de 1870 da cuenta de la publicación de la novela $L a$ vuelta de los muertos, cuya primer entrega "saldrá el 1 de junio siguiente". Véanse, Altamirano, Crónicas, 1989, vol. vII, t. 1, p. 497, y Crónicas, vol. vil, t. 2, p. 270. fundir ampliamente los conocimientos y de circular las ideas que impulsaban el progreso de las sociedades humanas. Ambos defendieron abiertamente la libertad de pensamiento, utilizando para este fin todos los recursos de la sociabilidad masónica.

Mientras Altamirano permanecía en México y era nuevamente electo magistrado de la Suprema Corte de Justicia para el periodo 1870-1873, Vicente Riva Palacio saldría del país para efectuar un largo viaje - dos años-por Europa.

A su regreso, su compromiso personal con Porfirio Díaz fue creciendo, al grado de tornarse enemigo declarado del presidente Sebastián Lerdo de Tejada. Llegó al extremo de devolver su despacho de general el 1 de marzo de 1875 para "poder expresar libremente sus opiniones", y en abril de este mismo año elevó una acusación contra este personaje ante el Gran Jurado de la Nación por violación expresa de algunos artículos constitucionales. ${ }^{33}$ Después del triunfo del Plan de Tuxtepec y del golpe de Estado de 1876, Vicente Riva Palacio ocupó el Ministerio de Fomento por cuatro años. En este elevado puesto lo secundó por breve tiempo, en el cargo de oficial mayor, su amigo Ignacio Manuel Altamirano. Pero, despechado al ver rechazados sus proyectos, Riva Palacio se separó del ministerio ${ }^{34}$ presentando exitosamente su candidatu-

${ }^{33}$ Archivo de Vicente Riva Palacio, Austin University of Texas Library (microfilm en el Archivo General de la Nación, rollo 95, doc. 109).

3430 de noviembre de 1880 . 
ra como diputado al Congreso de la Nación. A pesar de haber participado activamente en la campaña electoral del general González a la presidencia, se distanciaría cada vez más de éste, acabando por ser encarcelado como su opositor en 1883 . En prisión redactaría su parte de la magna obra de historia cuyo proyecto había propuesto y coordinado: México a través de los Siglos.

Cuando el general Porfirio Díaz regresó al poder en 1884 , prefirió alejar a Vicente Riva Palacio del país y lo nombró ministro plenipotenciario en España y Portugal. Cinco años más tarde, en 1889, Ignacio Manuel Altamirano también sería destinado a España con un cargo diplomático - el de cónsul general de los Estados Unidos Mexicanos. Pero para entonces la amistad entre los dos hombres se había diluido y apenas intercambiaron unas cartas de felicitación para año nuevo, a pesar de la cercanía de sus cargos que les hubiera brindado en otros tiempos un excelente pretexto para intercambiar correspondencia o visitas.

Sin embargo, el paralelismo en la trayectoria de aquellos hombres se mantuvo hasta la muerte, pues ambos fallecieron lejos de la patria por cuya libertad y progreso tanto habían combatido. Altamirano murió primero, en febrero de 1893, en San Remo, Italia, donde se había refugiado para mitigar el asedio de los inviernos europeos sobre su friolenta complexión de sureño. Vicente Riva Palacio lo hizo tres años después, en Madrid, después de alcanzar los mayores éxitos diplomáticos. Ocupaba una posición de alta relevancia en la vida social de la capital españo. la gracias a su vasta cultura, a su exquisita cortesía, al carisma desenfadado de su independencia intelectual. Alcanzó en tierra extraña el reconocimiento y los honores que tan parcamente le había concedido la suya propia, quizá porque la sombra poderosa y trágica de su abuelo el general Guerrero agigantó siempre ante los ojos de sus rivales políticos el "peligro" que podía constituir su talento y la orgullosa independencia de su criterio.

\section{BIBLIOGRAFIA}

-Archivo de Vicente Riva Palacio, en Austin, University of Texas Library.

- Altamirano, Ignacio M. et al., Ensayos literarios de la Sociedad Netzahualcoyoth, Imprenta de Ignacio Escalante, México, 1869.

-Altamirano, Ignacio Manuel, Obrascompletas. Crónicas, tomos 1 y 2, SEP, México, 1987 , vols. VII y VIII.

SEP, México, 1986, vol. I.

Obras completas. Discursos, , Obras completas. Epistolario, t. 1 (1850-1899), CNCA, México, 1992, vols. XIX y XXI.

Obras completas. Obras históricas, SEP, México, 1986, vol. II.

, Obras completas. Periodismopolítico, CNCA, México, 1989, vol. XVIII, t. 1.

-Fuentes Díaz, Vicente, Ignacio M. Altamirano, triunfo y viacrucis de un escritor liberal, Gobierno de Guerrero, México, 1988.

-García Reynoso, Melchor, Genealogía del maestro Igancio Manuel Altamirano, Instituto Guerrerense de la Cultura, Tixtla de Guerrero, 1991.

-Ruiz, Eduardo, Historia de la guerra de Intervención en Michoacán, Balsal, Morelia, 1973. 